\title{
Effect of quinidine on electrical and motor activity of canine small bowel ${ }^{1}$
}

\author{
J. MARSHALL GARRETT, JERRY F. SCHLEGEL, AND CHARLES F. CODE \\ From the Section of Physiology, Mayo Clinic and Mayo Foundation, and the Mayo Graduate School of Medicine, \\ University of Minnesota, Rochester, U.S.A.
}

EDITORIAL COMMENT This is a valuable contribution to knowledge of the way in which drugs may affect intestinal motility. A study on the effects of quinidine exemplifies the use of an elegant experimental technique in which the electrical activity in the wall of the gut, the intraluminal pressure, and the transit rate of intestinal contents are related. The results with quinidine are very interesting and further studies of this type should advance our understanding of gastrointestinal pharmacology.

Quinidine sometimes causes diarrhoea, which may be the consequence of hypermotility. This study was undertaken to determine whether quinidine alters the motor action of the small bowel of dogs. The motor action of the bowel was assessed by determination of the electrical activity in the muscle of its wall, its intraluminal pressure, and its radiological appearance before and after the administration of quinidine.

\section{METHODS AND PROCEDURES}

Electrical and pressure characteristics of the small bowel were observed during 15 tests on seven dogs. Two dogs had duodenal Biebl loops (1930), three had jejunal MannBollman fistulas (1931), and two had ileal Thiry-Vella loops. Two intact dogs were observed radiologically. The animals were trained to lie quietly during tests, without anaesthesia. They were fasted at least 22 hours before observations were made.

Smooth-muscle electrical potentials were detected in the dogs with Biebl loops by inserted stainless steel electrodes (Bass, Code, and Lambert, 1961) and in the other dogs by chronic, indwelling silver-silver chloride electrodes which had been sewn to the surface of the bowel at a prior operation (McCoy and Bass, 1963; Allen, Poole, and Code, 1964) or by intraluminal electrodes placed in the bowel during the tests (Garrett, Schlegel, and Hoffman, 1963; Christensen, Schedl, and Clifton, 1964). An indifferent electrode under the skin of the thigh served as a reference. The five-minute period immediately preceding administration of quinidine was used as a control, and the effects of quinidine were estimated during the second, sixth, and eleventh minutes after its administration. The cycles of the basic electrical rhythm were counted in each period and their frequency expressed as cycles per minute. The number of cycles of basic electrical rhythm on which 'spike' or 'fast' activity was superimposed was enumerated, and their incidence was

${ }^{1}$ This investigation was supported in part by research grant A-2015 from the National Institutes of Health, Public Health Service, U.S.A. expressed as a percentage of the total number of cycles.

Intraluminal pressures were conducted to strain-gauge transducers by water-filled polyethylene tubes. In most tests the ends of the tubes within the gut were open; in some they were covered with tiny balloons. The detecting tips were placed as close as possible to the location of the electrodes. The incidence, duration, and amplitude of type I pressure waves were measured during the same periods as the electrical activity was analysed. The coincidence of spike potentials with pressure changes was noted during these periods. In an attempt to define further the relationship of spike potentials to contractions, 100 consecutive cycles of the basic electrical rhythm, beginning one minute after quinidine administration, were examined, and the incidence of spike potentials and contractions during this period was determined.

The electrical potentials, pressures, respiratory excursions, and, in some tests, heart rate, were recorded simultaneously on a pen-writing oscillograph.

Four dogs, two with Biebl loops and two intact, were observed radiologically. By means of a gastric tube, 100 ml. of radiopaque material was placed in the stomach of each animal. Fluorographic observations, cineradiographs, and simple radiographs were made as the material traversed the small bowel. Control tests and tests after quinidine administration were done on each dog on different days. Tests were repeated on two dogs to determine reproducibility. In each dog the time required for the radiopaque material to reach the large bowel after quinidine administration was expressed as a percentage of the time required in the control tests. The character of the contractions of the bowel was studied in the cineradiograph, and their appearance in the control periods was contrasted with that after quinidine.

Quinidine gluconate (Lilly) was administered intravenously. A dose of $4 \mathrm{mg}$. $/ \mathrm{kg}$. body weight was most commonly used. (This is the amount often recommended for the control of cardiac arrhythmia in patients.) The intravenous route was used to prevent local irritation by the drug. Attempts were made to produce diarrhoea by 
TABLE I

SMOOTH-MUSCLE ELECTRICAL ACTIVITY IN SMALL BOWEL OF SEVEN DOGS BEFORE AND AFTER QUINIDINE ADMINISTRATION

Part of Bowel Dose of Quinidine No. of No. of Basic Electrical Percentage of Basic Electrical Rhythm Cycles with Tested (mg./kg.) Dogs
Tests
Rhythm (cycles/min. ${ }^{1}$ ) Action Potentials

Control Minute-period after Quinidine Injection

\begin{tabular}{|c|c|c|c|c|c|c|c|c|}
\hline & & & & & & Injection & & \\
\hline & & & & & & Second & Sixth & Eleventh \\
\hline $\begin{array}{l}\text { Duodenum } \\
\text { Jejunum } \\
\text { Ileum }\end{array}$ & $\begin{array}{l}4 \\
1 \\
4 \\
4 \\
2\end{array}$ & $\begin{array}{l}3 \\
2 \\
1 \\
1 \\
1\end{array}$ & $\begin{array}{l}7 \\
4 \\
2 \\
1 \\
1\end{array}$ & $\begin{array}{l}18 \text { to } 19 \\
14 \text { to } 15 \\
10 \text { to } 12\end{array}$ & $\begin{array}{l}29 \\
55 \\
61 \\
61 \\
78\end{array}$ & $\begin{array}{r}87 \\
90 \\
99 \\
91 \\
100\end{array}$ & $\begin{array}{r}91 \\
66 \\
100 \\
86 \\
100\end{array}$ & $\begin{array}{r}60 \\
73 \\
100 \\
100 \\
78\end{array}$ \\
\hline
\end{tabular}

${ }^{1}$ Frequency of basic electrical rhythm not changed by quinidine.

repeated injections of quinidine to two dogs. One injection containing $4 \mathrm{mg}$. $/ \mathrm{kg}$. body weight was given the first day, and an additional injection of $4 \mathrm{mg} . / \mathrm{kg}$. was added each day so that on the fourth day each dog received four injections totalling $16 \mathrm{mg}$.

\section{RESULTS}

The frequency of the basic electrical rhythm, which was 18 to $19 / \mathrm{min}$. in the duodenum, 14 to 15 in the jejunum, and 10 to 12 in the ileum, was not altered by quinidine. The number of cycles of the basic electrical rhythm on which fast activity was superimposed always increased after quinidine (Table I). Most dogs had periods of a minute or more after the injection of quinidine when all cycles of the basic electrical rhythm showed fast activity. Such a high incidence did not occur in the control periods. When the dose of quinidine was $4 \mathrm{mg}$./ $\mathrm{kg}$., the effects were evident within a minute (mean 26 seconds). The duration of action was 12 minutes in the duodenum, 20 minutes in the jejunum, and 13 minutes in the ileum.

In all tests after quinidine administration, contractions of the bowel occurred more frequently and their pattern became rhythmic (Fig. 1 and Table II).

The sudden increase in the incidence of fast electrical activity after quinidine was simultaneous with the increase in the number of contractions. When 100 consecutive cycles of the basic electrical rhythm recorded after quinidine were examined in

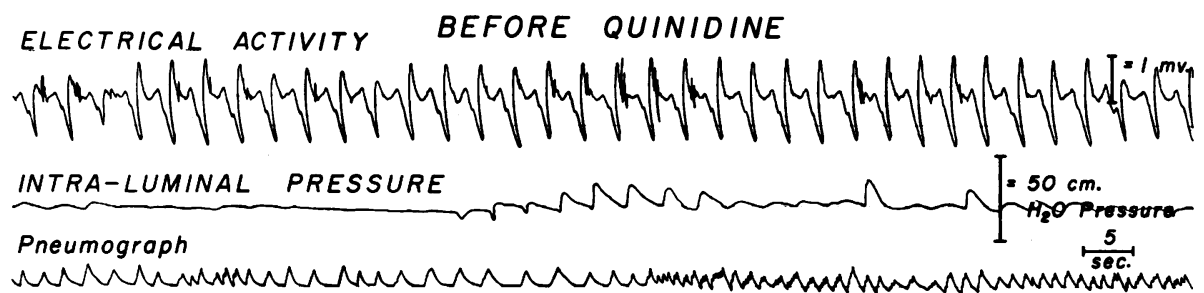

AFTER QUINIDINE

$7^{\text {th }}$ and $8^{\text {th }}$ minute

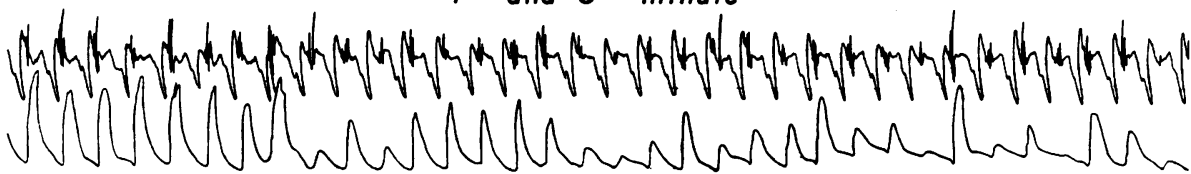

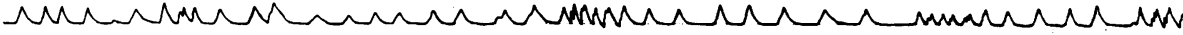

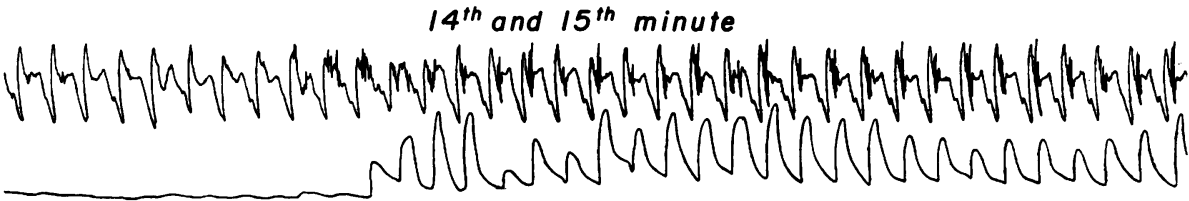

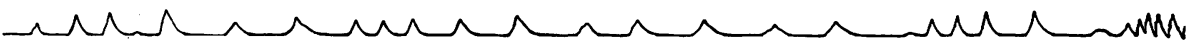

FIG. 1. Simultaneous recording of mural electrical activity and intraluminal pressure from adjacent sites of small bowel in dog before and after intravenous injection of quinidine gluconate. About $50 \%$ of the cycles of the basic electrical rhythm include action potentials before quinidine administration whereas they all do during the seventh and eighth minutes after its administration. Effect of quinidine was wearing off during fourteenth and fifteenth minutes. 
seven tests on five dogs giving a total of 700 cycles, fast activity was superimposed on $669(96 \%)$. Contractions accompanied $653(98 \%)$ of the 669 bursts of fast activity. The associations were not as close during the control period. For example, 517 cycles of the basic electrical rhythm were examined in the five-minute period just before quinidine was given. Of these, $213(41 \%)$ showed fast activity. Contractions were recorded with $136(64 \%)$ of the 213. The lesser incidences of recorded contractions with cycles of the basic electrical rhythm containing fast activity during the control periods were due probably to the variable strength of control contractions, some being so feeble that no pressure change was detected (Table II, mean pressure of control contractions $5 \mathrm{~cm}$. water).

The time required for barium to reach the large bowel in the control observations ranged from 105 to 150 minutes, the mean being 128 minutes. After quinidine was given $(4 \mathrm{mg} . / \mathrm{kg}$. body weight), barium entered the large bowel much sooner, the mean being 44 minutes (range 18 to 67 minutes).

During control observations, the predominant motor activity of the small bowel was rhythmic segmentation (type I waves) although not all parts of the bowel were active at the same time. After quinidine was given, the entire length of the small bowel became active. Much of the motility was rhythmic segmentation, but the lumen appeared to narrow and progression of barium in it was more rapid and much more predominantly analward than in control
TABLE II

CONTRACTIONS AND INTRALUMINAL PRESSURES IN SMALL BOWEL OF DOG BEFORE AND AFTER ADMINISTRATION OF

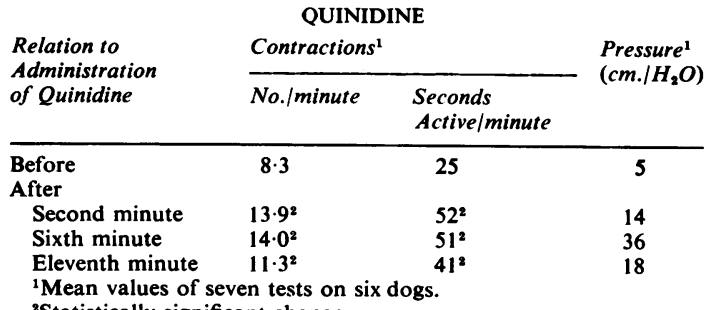

${ }^{2}$ Statistically significant change.

studies (Fig. 2). In some segments the narrowing became more permanent and was accompanied by disappearance of segmental activity. When this occurred, long segments of the bowel appeared as a 'ribbon' with the ribbon of barium moving quickly in one direction, presumably analward.

Watery diarrhoea did not occur in the two dogs given increasing quantities of quinidine on four successive days. Both dogs passed loose stools, however: one on the third and fourth days, and the other on the fourth day.

\section{DISCUSSION}

Two types of electrical potentials have been regularly recorded from the canine small bowel (Puestow, 1932; Bozler, 1946; Ambache, 1947; Milton, Smith, and Armstrong, 1955; Holaday, Volk, and Mandell, 1958; Daniel, Carlow, Wachter, Sutherland, and
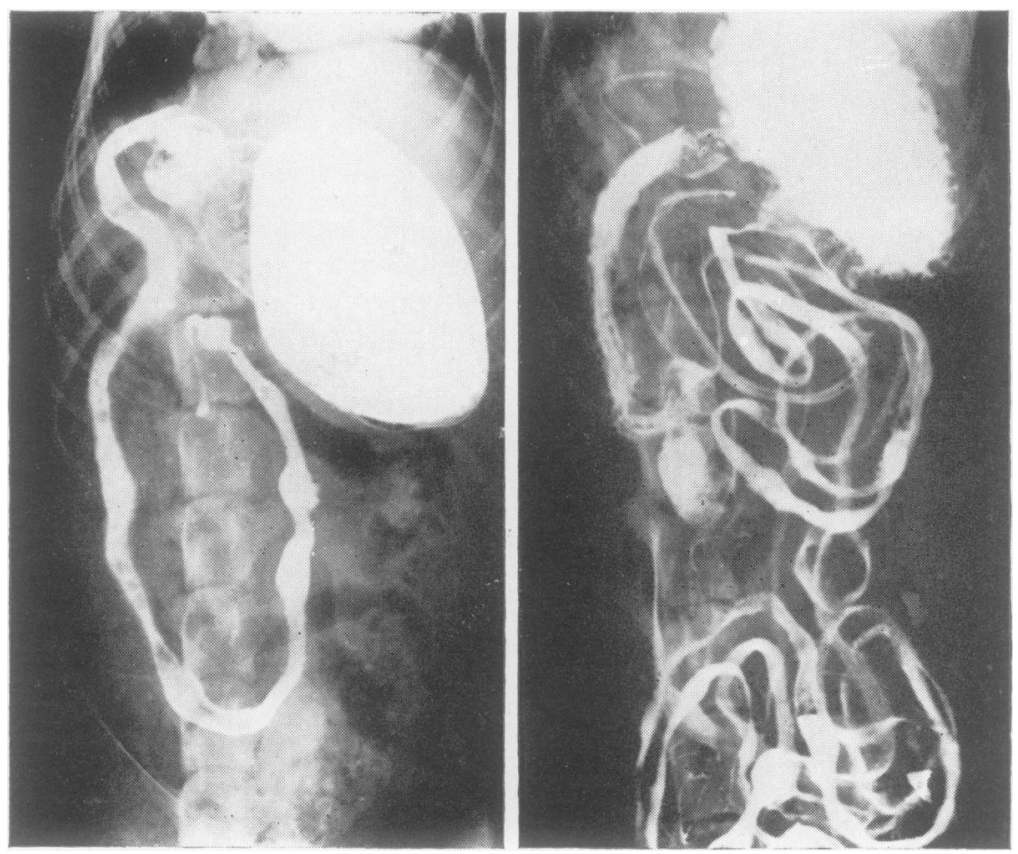

FIG. 2. Distribution of barium in stomach and small bowel of dog 30 minutes after its administration when quinidine had not been given (left panel) and 30 minutes after simultaneous administration of barium and $4 \mathrm{mg} . / \mathrm{kg}$. of quinidine (right panel). 
Bogoch, 1959; Bortoff, 1961; Bass et al., 1961; Nakayama, and Nanba, 1961; McCoy and Bass, 1963; Allen et al., 1964). One, designated as the basic electrical rhythm, is omnipresent and cyclic. The other is typically identified as a burst of fast or spike potentials superimposed on a cycle of the basic electrical rhythm. The bursts of fast activity are associated with contractions of the gut. Our results confirm these general findings. They also indicate that the contractions associated with the fast electrical activity are type $I$ in character. When these contractions are in a cyclic sequence, they produce rhythmic segmentation (Cannon, 1902). Since fast, spike potentials are associated with contractions, their most appropriate designation is action potentials.

The results demonstrate that quinidine stimulates the motor activity of the small bowel of dogs. The action is specific; the incidence of action potentials is increased without any alteration in the frequency of the basic electrical rhythm on which they are superimposed. The increased incidence of bursts of action potentials is directly related to an increase in the incidence of rhythmic segmental (type I) contractions of the small bowel. These effects produced a shortening of the transit time of barium through the small bowel.

The increase in rhythmic segmentation in the bowel with quinidine was visible in the cineradiographs. At the peak of quinidine's action a ribbonlike outline of segments of the bowel also was observed. Thus, the effect of quinidine on the contents did not seem to be due just to increased rhythmic segmental contractions, which involve mainly the circular muscle, but also possibly to contraction of the longitudinal coat. Contractions of the longitudinal fibres, when combined with contraction of circular fibres, even in segments, would produce a narrowed lumen extending over the length of firmly contracted longitudinal fibres. Strong contraction of longitudinal fibres could obliterate visualization of contraction of narrow segments of circular fibres, and this was just the appearance of the 'ribbons' of bowel.

Most recent evidence indicates that in the small bowel the conducting system for the basic electrical rhythm resides in the longitudinal coat of smoothmuscle fibres (Daniel and Champan, 1963; Burnstock, Holman, and Prosser, 1963). Quinidine did not increase the frequency of the basic electrical rhythm or its configuration, but it did alter the connexion between it and the circular muscle fibres in such a way that action potentials and the associated contractions occurred with each cycle of the basic electrical rhythm. Quinidine must act at the site of or on the chemical processes representing the junction or connexion between the basic electrical rhythm and the contractile process of the muscle fibres. Our results indicate that the longitudinal as well as the circular fibres are affected. Direct coupling of the rhythmic electrical activity of the bowel with the smooth muscle so that it contracted with each electrical cycle may be related to the reduction in irregularities of cardiac contractions that may follow administration of quinidine; possibly, it strengthens the coupling of the cardiac muscle with rhythmic electrical activity of nodal tissue. In some respects the gut with its pace-setting basic electrical activity and the associated muscle contractions resembles a primitive cardiac system.

\section{SUMMARY}

Quinidine gluconate given intravenously to dogs increased the incidence of action potentials in the wall of the small bowel and of contractions detected by intraluminal pressure and observed by cineradiography. Associated with the increased muscular activity, the time required for radiopaque material to traverse the small bowel was reduced by quinidine.

\section{REFERENCES}

Allen, G. L., Poole, E. W., and Code, C. F. (1964). Relationships between electrical activities of antrum and duodenum. Amer. $J$. Physiol., 207, 906-910.

Ambache, N. (1947). The electrical activity of isolated mammalian intestines. J. Physiol. (Lond.), 106, 139-153.

Bass, P., Code, C. F., and Lambert, E. H. (1961). Motor and electric activity of the duodenum. Amer. J. Physiol., 201, 287-291.

Biebl, M. (1930). Graphische Darstellung der Darmbewegungen an der in einem Hautschlauch exventerierten Darmschlinge. Klin. Wschr., 9, 1674-1675.

Bortoff, A. (1961). Slow potential variations of small intestines. Amer. J. Physiol., 201, 203-208.

Bozler, E. (1946). The relation of the action potentials to mechanical activity in intestinal muscle. Ibid., 146, 496-501.

Burnstock, G., Holman, M. E., and Prosser, C. L. (1963). Electrophysiology of smooth muscle. Physiol. Rev., 43, 482-527.

Cannon, W. B. (1902). The movements of the intestines studied by means of the röntgen rays. Amer. J. Physiol., 6, 251-277.

Christensen, J., Schedl, H. P., and Clifton, J. A. (1964). The basic electrical rhythm of the duodenum in normal human subjects and in patients with thyroid disease. $J$. clin. Invest., 43, 16591667.

Daniel, E. E., Carlow, D. R., Wachter, B. T., Sutherland, W. H., and Bogoch, A. (1959). Electrical activity of the small intestine. Gastroenterology, 37, 268-281.

_- and Chapman, K. M. (1963). Electrical activity of the gastrointestinal tract as an indication of mechanical activity. Amer. $J$. dig. Dis., 8, 54-102.

Garrett, J. M., Schlegel, J. F., and Hoffman, H. N., II. (1963). Intraluminal detection of intestinal electrical activity. Fed. Proc., 22, 225.

Holaday, D. A., Volk, H., and Mandell, J. (1958). Electrical activity of the small intestine with special reference to the origin of rhythmicity. Amer. J. Physiol., 195, 505-515.

McCoy, E. J., and Bass, P. (1963). Chronic electrical activity of gastroduodenal area: effects of food and certain catecholamines. Ibid., 205, 439-445.

Mann, F. C., and Bollman, J. L. (1931). A method for making a satisfactory fistula at any level of the gastro-intestinal tract. Ann. Surg., 93, 794-797.

Milton, G. W., Smith, A. W. M., and Armstrong, H. I. O. (1955). The origin of the rhythmic electropotential changes in the duodenum. Ouart. J. exp. Physiol., 40, 79-88.

Nakayama, S., and Nanba, R. (1961). Electrophysiological studies on the intrinsic reflex. Jap. J. Physiol., 11, 499-505.

Puestow, C. B. (1932). The activity of isolated intestinal segments Arch. Surg., 24, 565-573. 